\title{
The Impact of Electric Vehicle Charging Station on the Grid
}

\author{
Qun Liu ${ }^{a}$, Hui Fang ${ }^{b}$, Jingsong Wang ${ }^{c}$, Shaopeng Yan ${ }^{d}$
}

State Grid Henan Electric Power Company Luoyang Power Supply Company, Luoyang, China

ayshp-yshp@163.com, ${ }^{\mathrm{b}} 1015903240 @ q q . c o m$

Keywords: Electric vehicle charging station, impact

\begin{abstract}
With the popularity of electric vehicles, electric vehicles charging station its facilities in the near future will also usher in a lot of construction. A large number of electric vehicle charging stations connected to the grid, will have a major impact on the power grid, voltage and current. In order to be better able to provide technical support for the construction of charging stations, electric car charging stations to reduce the negative impact on the power grid, improve economic efficiency, we study the effects of electric vehicle charging station to the power grid caused by load characteristics from the following aspects, and proposed corresponding solutions.

Keywords: Electric vehicle charging station; load modeling; coordination charge; flow calculation.
\end{abstract}

\section{Introduction}

In recent years, as the global benefits of a serious energy crisis, alternative energy and energy for sustainable development is imminent, clean, renewable energy for its energy resources to become the first choice of many countries. Since then, many countries of the world, the United States, Japan, $\mathrm{EU}$ and so the development of electric vehicles as a way to resolve important in planning the national grid and the Ministry of Industry, the Chinese government will develop electric vehicles as an important development plan to support, from the beginning of the Ninth Five-Year Plan will be the development of electric vehicles as an important issue. 2012 Ministry of Science issued a "electric vehicle technology development," second five "special plan", according to the plan, "five-second" period, China will promote the application of hybrid technology as soon as possible, the development of small electric vehicles and plug-in hybrid powered electric vehicles; in the medium term (and the resulting hybrid technology in broad-based applications, increase small electric cars and plug-in hybrid promotion efforts; in years, pure electric drive technology will gradually dominate, Through the development of pure electric vehicles and fuel cell vehicles, to achieve a significant reduction in emissions. To this end, "five-second" period, China's electric vehicles will establish a "pure electric drive" technology transformation strategy; play to our advantage and comparative advantage, for "pure electric drive" the implementation of the automobile industry technology transformation strategy to accelerate the development of "pure electric drive" electric vehicle products.

It includes characteristics of grid load that electric vehicle charging impact on the grid, harmonic influence, voltage and current shocks, unbalanced load influence and power loss affected. Load characteristics, since the user charging habits has great randomness and uncertainty go of, currently mainly used two approaches to simplifying assumptions and mathematical and statistical methods. Harmonic party and, many researchers use different methods and tools for harmonic problems produced electric vehicles scale access were analyzed, such as the use of statistical probability law of large numbers and the central limit theorem, a multi-harmonic source harmonic wave mathematical model to study the harmonic current characteristics of a plurality of electric vehicle charging machine generated. 


\section{Load of Electric Vehicle Charging Stations}

As more and more electric vehicles into the social production and living, the demand for electrical energy will affect the existing power grid city planning system, thereby affecting the planning and development of electric vehicle charging systems. Construction planning, building capacity and other electric vehicle charging station is mainly affected by the following factors:

\subsection{Electric Vehicle Overall Ownership}

Urban residents in electric car ownership is an important factor in electric vehicle charging amount, the higher penetration of electric vehicles, the required electric car charging stations and charging machine capacity is higher. With the increasing popularity of electric vehicles, the new city because of the acceptance of the new electric cars will be higher than the old city, so the overall demand for new city charge amount will be slightly higher than the old town.

\subsection{Electric Vehicle User Habits and Mode of Operation}

Different electric vehicle applications, the charging requirements also vary. In the bus operation mode, the bus can be directly fixed with a fixed bus station charger for charging, either by rapid charger for fast charging enough power for the next departure, you can also use the night buses suspended electricity peak hours regular charge; try to set up a bus stop a few quick charger to meet some overtime or emergency mission bus rapid charging, per charge power required to meet a single voyage. Taxis and public service vehicles and other vehicles travel more random units, travel time cannot be determined, especially taxi short of charging relatively high speed requirement, therefore, should be more concentrated area for taxis and public service vehicles, additional electric vehicles charging stations to meet the requirements of taxi pick-charge. At the same time, the corresponding charging facilities should be built near the stadium in government offices around town car concentrated area or priorities.

\subsection{Electric Vehicle Battery Characteristics}

It has been put into the market for electric cars belong to two different extremes, including smaller capacity, mileage small cars and short battery life carry a lot of mileage universal long buses, two types of battery charging in different ways, the current best charging rate varies between. Currently there is commonly used charging constant voltage constant current and constant power of two, it should be based on their different characteristics of different battery charging methods.

\subsection{Planning and Construction of Electric Vehicle Charging Station Location}

Electric vehicle charging station charging station sites have a very significant impact loads, at this point, charging stations similar to traditional gas station, charging station needs a higher penetration of electric vehicles in areas surrounding the construction of a natural high, such as new urban planning to support key enterprises, and so on. Further along the highway charging station is also charging station in a class of relatively high demand, due to the high-speed road car usually require fast-charge, so this type of fast charging stations charging more to the main power level is higher than normal charge station.

\section{Impact on The Load after The Grid Electric Car Charging Stations Connected to The Grid}

Electric car charging stations connected to the grid in the future belong to grid power loads, it may result in redistribution of power load, causing the trend of change and net loss increases, as shown Nonconforming charging means charging users according to their needs and charge habit, anytime, anywhere to the electric vehicle charging. Coordination charging means as shown in the relevant policy and smart car charger constraint conditions, electric vehicle users in accordance with the needs of an orderly grid charging. According to the research results, the non-coordinated charging conditions, the electric car in the night will be a substantial peak power load connected to the grid, resulting in increased power load and voltage deviation increases, the grid network losses increase, resulting in the transmission efficiency of the grid and decline in the quality and 
coordination of power charge is based on the grid requires the user as part of the smart grid, passive charging mode, when the grid is in the low load, you can use an electric vehicle charging to balance low, less frequent stopping and starting backup power station power resources frequent scheduling.

Grid load curve directly reflects the needs of users, reasonable forecast load curve on the grid schedule and run a very big role in guiding, affect the charging station grid system load curve mainly by the battery charging time and charging decisions, as the charging station a lot of access to the grid, load curve forecasting the traditional mode error may occur, so the impact of electric vehicle charging stations for further simulation load curve analysis. When the charging schedule during non-peak hours to improve the power grid load rate, and arrange charging during peak hours will accelerate grid load rate. Gas stations operate independently and can be different, in order to ensure the safety of the grid, smooth and efficient, electric vehicle charging facilities for energy supply network, intelligent higher requirements while charging.

In order to improve the efficiency of the power system to minimize the impact of large-scale electric car on the grid, first, power scheduling arrangements for electricity production sector in inches, should ensure enough power margin and power system related electrical equipment in time to upgrade, to ensure the power load increase inch, the device does not overload. Secondly, the power sector can adjust the price reasonable measures to guide and encourage ordinary users to try to preclude the charging of a coordinated strategy to avoid peak charging. With the development of the smart grid, intelligent vehicle terminal will be put into the market, it became part of the electric power grid steam, according to the needs of the grid charging, and this measure will also provide stable operation of the power system to provide protection.

\section{The Impact on The Power System after Electric Car Charging Stations Connected to The Grid}

Since a large number of electric charging stations steam, electric power systems have a very serious impact and affect the stability. In order to ensure a stable power supply system, power supply system is required to have the ability to impact and shock loads must be addressed with inches to the impact of the power supply system problems. Possible impacts following main points:

\subsection{Affect The Integrity of The Electricity Network}

The main components of the power system, including generators, transmission lines, users and the necessary protection and control devices, to secure stable operation of the power system to protect network integrity, and will not run in the process to make it happen splitting and load shedding phenomenon, to maintain the normal operation of the power system is necessary. Due to the impact of the load has a certain influence on the voltage and current and power output of the power system, leading to the occurrence of certain aspects of the transmission process parameters change. This change is changing over time, if this phenomenon does not decay over time or the occurrence of a longer duration, can cause dramatic changes in the parameters of the power system, causing some power network operation control means, the destruction of the power network integrity, but also to the power supply system loses stability.

\subsection{Affect The System Frequency Stability}

Frequency stability is to determine the index of the entire power system stability. When active relatively large load access system occurs, the generator output increases, causing the whole network frequency decreases. As the frequency decreases will cause a decline in generator speed, eventually causing the network generator out of step. Consequences arising out of the dramatic changes in the system load, power system protection devices act quickly lead to the collapse of the entire system. Thus ensuring the stability of the electricity network frequency is an important guarantee for ensuring power supply. 


\section{Summary}

Electric car charging stations on the grid impact analysis critical load modeling is charging stations, since electric car users belonging to randomness, dispersion of relatively high population, were analyzed during the charging behavior, we should take into account all possible factors of equipment and human factors. Wood paper uses mathematical and statistical methods, the establishment of a charging station Gaussian distribution load model for future electric vehicle charging station operation and load forecasting to provide a reliable basis.

\section{Reference}

[1]Sun Y T, Zhang H D, Li Z H, et al. The Impact of Electric Vehicle Charging Stations on Power Flow Calculation and Grid Loss[J]. Applied Mechanics \& Materials, 2013, 325-326.

[2]Schey S, Scoffield D, Smart J. A First Look at the Impact of Electric Vehicle Charging on the Electric Grid in the EV Project[J]. Evs26 Electric Vehicle Symposium, 2012.

[3]Leou R C, Teng J H, Su C L. Modelling and verifying the load behaviour of electric vehicle charging stations based on field measurements[J]. Iet Generation Transmission \& Distribution, 2015.

[4]Jia Y Y, Ramachandaramurthy V K, Kang M T, et al. Modeling of electric vehicle fast charging station and impact on network voltage[C]// Clean Energy and Technology (CEAT), 2013 IEEE Conference on. IEEE, 2013:399 - 404.

[5]Grahn P, Rosenlind J, Hilber P, et al. A method for evaluating the impact of electric vehicle charging on transformer hotspot temperature[C]// Innovative Smart Grid Technologies (ISGT Europe), 2011 2nd IEEE PES International Conference and Exhibition on. IEEE, 2011:1 - 8.

[6]Liu M Z, Zhang J, Jian-Cheng Y U, et al. Impact of electric vehicle charging facilities on power grid steady state[J]. Advanced Technology of Electrical Engineering \& Energy, 2013. 